\title{
CAPITALISMO, QUESTÃO SOCIAL E (DES) PROTEÇÃO SOCIAL DE ADOLESCENTES AUTORES DE ATO INFRACIONAL EM TEMPOS DE BARBÁRIE
}

\author{
Capitalism, Social Issue and Social Deprotection of Adolescent Officers in Barbarian Times
}

\author{
Bruna Carolina Bonalume, Adriana Giaqueto Jacinto
}

Universidade Estadual Paulista, Brasil

KEY WORDS

Adolescence

Criminality

Social issues

Social deprotection

\section{ABSTRACT}

The debate surrounding the adolescent who commits infringements is permeated by various conceptions and ideologies, which are grounded in a class society governed by capital. The classist, exclusionary and selective character is rooted in the Brazilian juvenile penal system and makes explicit the attempt to maintain the logic of marginalization, criminalization of poverty and blatant naturalization of the social issue. This scenario brings against the background the perversity of the violation of the fundamental rights of this population to the detriment of the expansion of public policies that are really capable of sustaining a model of integral social protection.

\section{PALAVRAS-CHAVE E}

Adolescencia

Criminalidade

Questão social

Desproteção social

\section{RESUMO}

O debate em torno do adolescente que comete atos infracionais é atravessado por várias concepções e ideologias, estando essas alicerçadas em uma sociedade de classes regida pelo capital. 0 caráter classista, excludente e seletivo mostra-se enraizado no sistema penal juvenil brasileiro e deixa explícita a tentativa de manutenção da lógica da marginalização, da criminalização da pobreza e descarada naturalização da questão social. Esse cenário traz como pano de fundo a perversidade da violação dos direitos fundamentais dessa população em detrimento da ampliação de políticas públicas realmente capazes de sustentar um modelo de proteção social integral.

Recebido: 29/04/2020

Aceite: $20 / 12 / 2020$

\section{GLOBAL KNOWLEDGE}




\section{Introdução}

O tempo presente tem sido marcado por retrocessos dos direitos sociais, avanço do conservadorismo, valorização de discursos e práticas que demarcam o cunho coercitivo e opressor do modo como o Estado responde à intensificação das expressões da questão social. Além disso, estamos imersos em uma crise política, econômica e ética sem precedentes, que parece colocar em xeque até mesmo o processo democrático brasileiro. As desigualdades sociais, consolidadas no modelo vigente de sociedade, são resultado da riqueza socialmente produzida e acessada por poucos, bem como do processo de concentração do poder. A pobreza se alastra ao passo que aumenta a distância entre ricos e pobres no Brasil, o que não se trata de uma mera coincidência. Vivemos uma realidade em que a ampliação das riquezas contrasta fortemente com o aprofundamento da miséria e as classes sociais invisibilidades pelo Estado e pelas políticas sociais acabam por incorporar a grande massa de sobrantes, a essa soma-se os adolescentes e jovens autores de atos infracionais.

0 debate em torno do adolescente que comete atos infracionais é atravessado por várias concepções e ideologias, bem como por projetos antagônicos em disputa na sociedade, os quais estão alicerçados em uma sociedade de classes regida pela ordem do capital. 0 caráter classista, racista, excludente e seletivo mostrase enraizado no sistema penal juvenil, deixando explícita a tentativa de manutenção da lógica da marginalização, da criminalização da pobreza e descarada naturalização da questão social. Esse cenário traz como pano de fundo a perversidade da violação dos direitos de adolescentes e jovens, produzida e reproduzida em um modelo de sociedade que se sustenta pela órbita do capitalismo vigente em detrimento da ampliação de políticas públicas realmente capazes de sustentar um modelo de proteção social integral.

Importante considerar que a prática de atos infracionais é frequentemente anunciada na grande mídia, em geral associada à imagem de um adolescente "perigoso", que precisa ser contido para o funcionamento harmônico e burguês da vida social. Nesse cenário intensificam-se os debates em torno da redução da maioridade penal como resposta do Estado no combate a vadiagem e à ideia de impunidade tão disseminada nos discursos societários. Contudo, esse debate não ultrapassa o limite da superficialidade e ignora as lacunas e limites do sistema protetivo proposto pelo Estatuto da Criança e do Adolescente (ECA).

Desse modo, torna-se imprescindível compreender a criminalidade juvenil na sua complexidade como fenômeno dotado de contradições, fruto de uma sociedade demarcada por desigualdades, no campo econômico, social, político e cultural. Sociedade essa, que se reproduz na órbita de um sistema capitalista, produzindo assim, distintas formas de viver a adolescência.

Para adentrarmos nesse campo tão árido, serão tecidas discussões construídas na perspectiva de contextualizar a questão social, suas expressões e o o papel do Estado nesse contexto. Por fim, traremos reflexões e dados que contextualizam a o cenário das práticas infracionais no cenário brasileiro em consonancia com a violação de direitos vivenciadas por esses adolescentes.

\section{Intensificação das expressões da questão social e o papel do Estado no cenário brasileiro}

Para Iamamoto (2001) a questão social diz respeito ao conjunto das expressões das desigualdades sociais engendradas na sociedade capitalista, onde a classe trabalhadora, por meio da sua força de trabalho, produz riquezas e bens que serão apropriados e acumulados por uma dada classe dominante, em um contexto em que acumulação de capital não equivale à igualdade, ainda que esta última esteja garantida juridicamente a todos os cidadãos. Portanto, a questão social é uma categoria que expressa a contradição fundamental do modo de produção capitalista.

Cabe considerar que nesse contexto o Estado assume o trato com a questão social, sem que isto ameace a lógica reprodutiva do capital ou denuncie a estrutura social dessa relação, são intrínsecas as contradições inerentes ao próprio capitalismo. Portanto, fragmentar a questão social e fazer com que ela pareça um problema 
Capitalismo, questão social e (des) proteção social de adolescentes autores de ato infracional...

particular dos sujeitos sociais torna-se aqui uma clara estratégia. A respeito disso, Paulo Netto (2009) esclarece que a intervenção estatal sobre a questão social se realiza:

[...] fragmentando-a e parcializando-a. E não pode ser de outro modo: tomar a questão social como problemática configuradora de uma totalidade processual especifica é remetê-la concretamente à relação capital/trabalho- o que significa, liminarmente, colocar em xeque a ordem burguesa. Enquanto intervenção do Estado burguês no capitalismo monopolista, apolítica social deve constituir-se necessariamente em politicas sociais: as sequelas da questão social são recortadas como problemáticas particulares (o desemprego, a fome, a carência habitacional, o acidente de trabalho, a falta de escolas, a incapacidade física, etc.) e assim enfrentadas (Paulo Netto, 2009, p.39)

Assim, o Estado entra em cena, apresentandose como instituição neutra, que paira acima das classes, mas, que na verdade, tem poderes (e função) de vigiar e controlar a classe dominada em favor dos interesses da classe dominante.

Desse modo, o Estado internaliza, no campo de suas funções, o trato da questão social, como mais uma demanda colocada pela lógica da manutenção da ordem e para se legitimar socialmente. Para Marx (2010), o Estado jamais eliminará por completo os problemas sociais, através de sua ação e nem perderá o seu caráter de classe por se tornar mais um interventor, pois apenas adapta a sua forma às necessidades de expansão do capital.

Fica claro que há no atual contexto social uma nítida relação entre Capital e Estado, mutuamente relacionando-se no sentido de expansão do modelo econômico e, lembrando sobre o avassalador poder que opera, Bauman (2001, p.30) ainda adverte que "o Estado não exercerá seus poderes de outra forma a não ser por meio do controle", impactando de sobremaneira o cotidiano das classes mais vulneráveis.

0 aumento da repressão estatal, sobretudo com a população mais pobre, para Wacquant (2001, p. 10) constitui-se como uma verdadeira "ditadura sobre os pobres", é uma resposta do Estado Penal "às desordens pela desregulamentação da economia, pela dessocialização do trabalho assalariado e pela pauperização relativa e absoluta de amplos contingentes do proletariado urbano, aumentando os meios, a amplitude e a intensidade da intervenção do aparelho policial e judiciário".

As classes sociais invisibilizadas pelo Estado e pelas politicas sociais acabam por incorporam a grande massa de sobrantes, a qual se somam os adolescentes e jovens autores de atos infracionais. Podemos afirmar que nunca se falou tanto do envolvimento de adolescentes e jovens com o tráfico de drogas, roubos e, sobretudo, com a violência, que atinge índices alarmantes no cenário brasileiro. Esses adolescentes e jovens também recebem destaque principalmente pela mídia e acabam se tornando protagonistas desse verdadeiro campo de batalhas que se alastra em toda conjuntura nacional, a quem caberá o controle coercitivo do braço forte do Estado.

Evidentemente que essa punição não é dada a todas as juventudes, mas é imposta, sobretudo aos pobres, geralmente negros e moradores de periferias.

[...] os jovens em conflito com a lei, tomados como agressores da sociedade e invisibilizados como sujeitos de direitos recebem tratamento de punição. Paralelamente, vão sendo excluídos da sociedade e internados em instituições socioeducativas, relacionando-se com o sistema jurídico-político por meio de um movimento dicotômico que segrega a categoria da infância e da juventude pobre em vítimas e infratores (Scisleski et al., 2015, p. 514).

Entender o processo subjacente às tensões entre proteção e punição na realidade contemporânea supõe compreender, mais amplamente, a tensão entre classes presentes neste campo.

\section{Adolescentes autores de atos infracionais na cena contemporânea: contradições e lacunas do sistema socioeducativo}

De acordo com o Estatuto da Criança e do Adolescente (ECA) o adolescente em conflito com a lei é definido como aquele que se encontra na faixa etária que compõe a adolescência e comete ato infracional. Assim, um adolescente só pode ser considerado infrator quando for caracterizado pelos três aspectos a seguir: a) violou dispositivos 
legais que caracterizavam crime ou contravenção; b) foi-lhe atribuído ou imputado o cometimento de um ato infracional; c) após o devido processo, com respeito estrito às garantias, ele foi considerado responsável. (Brasil, 1990).

Para além das definições jurídicas, é necessário analisar o ato infracional enquanto um efeito de diversos fatores que resultaram neste tipo de ação. É somente nesse sentido que se pode definir o ato infracional sem préconceitos e julgamentos.

Segundo dados do Levantamento Anual referente ao ano de 2012 da Coordenação - Geral do SINASE (SNPDCA/SDH 2014), 20.532 adolescentes cumpriram medida socioeducativa em restrição e privação de liberdade (internação, internação provisória e semiliberdade), e 88.022 em meio aberto (prestação de serviços à comunidade e liberdade assistida) no Brasil.

Esse mesmo levantamento demonstra um quadro em que a medida socioeducativa de internação, que deveria ser aplicada em caráter de exceção, representa mais de $60 \%$ dentre todas as medidas aplicadas no Brasil:

A série histórica de restrição e privação de liberdade indica um aumento constante e regular desde 2010, com predominância para a aplicação da modalidade de internação (66\%). Destaca-se, ainda, o significativo número em internação provisória, representando $22 \%$ do total de adolescentes em 2014. (Brasil, 2018, p. 15)

Quanto à tipificação do ato infracional, no Brasil 46\% são análogos ao roubo, $24 \%$ análogo ao tráfico de drogas e 10\% (2.788) análogo ao homicídio. Os crimes hediondos, sobretudo contra a vida, são praticados em menor quantidade, embora a mídia geralmente amplie a magnitude dessas práticas. Sobre essa questão, Zaffaroni (2012, p 307) definiu como criminologia midiática:

A criminologia midiática cria a realidade de um mundo de pessoas decentes frente a uma massa de criminosos, identificada através de estereótipos que configuram um eles separado do resto da sociedade, por ser um conjunto de diferentes e maus. 0 eles da criminologia midiática incomodam, impedem de dormir com as portas e janelas abertas, perturbam as férias, ameaçam as crianças, sujam por todos os lados e por isso devem ser separados da sociedade, para deixar-nos viver tranquilos, sem medos, para resolver todos os nossos problemas. Para tanto, é necessário que a polícia nos proteja de suas ciladas perversas, sem qualquer obstáculo nem limite, porque nós somos limpos, puros e imaculados.

Desse modo, o aparelho midiático, em sua ideologia burguesa, contribui com o fetiche da estigmatização e criminalização das juventudes, ao passo que favorece a disseminação no imaginário social da ideia de sujeito perigoso, a quem não cabe a proteção integral e sim a dura mão do Estado.

Em relação ao perfil desses jovens constata-se que $91 \%$ são alfabetizados, sendo que a média etária de interrupção dos estudos se deu aos 14 anos, $74,8 \%$ faziam uso de entorpecentes, sendo maconha, cocaína e crack os mais presentes, respectivamente. 0 perfil dos adolescentes ainda é mais elucidativo se considerarmos os impactos da questão social na miséria do cotidiano. Dentro do quadro dos adolescentes em cumprimento de medidas de restrição e privação de liberdade no ano de 2014, mais de 55\% são negros e pardos, num claro recorte de raça/etnia e classe social (Brasil, 2018).

Essa condição agrava-se ainda mais quando nos referimos ao processo de reiteração do ato infracional, esse mesmo levantamento, afirma que $56,4 \%$ estavam cumprindo pela primeira vez a medida socioeducativa com privação de liberdade, enquanto $43,3 \%$ já haviam passado por essa mesma medida ao menos uma outra vez.

No Brasil, em 2014, foram registradas 48 mortes de adolescentes em unidades de internação para cumprimento de medida socioeducativa, o que representa uma média de quatro óbitos por mês, o dobro se comparado ao ano de 2013. Foram identificadas as seguintes causas para as mortes: conflito generalizado, conflito interpessoal, doença crônica, suicídio, morte natural súbita e a categoria outros. Destaca-se que a categoria "outros" foi apontada em $46 \%$ dos casos de óbitos, o que pode indicar uma dificuldade do Sistema em registrar essas informações e pouca atuação dos órgãos de fiscalização, monitoramento e controle social. (Brasil, 2018).

Como poderia ser traduzida esta categoria "outros"? O que ela informa? Não é no mínimo 
estranho que a quase metade das mortes no sistema socioeducativo brasileiro não tenha sido esclarecido? Pane no sistema ou um silêncio conveniente?

Segundo pesquisa realizada pelo Instituto Sou da Paz (2018, p.7), um quarto da amostra representativa dos jovens entrevistados ofereceu depoimentos espontâneos e consistentes de agressões físicas por parte de servidores da Fundação CASA, "expondo a necessidade de assegurar um processo de capacitação e treinamento contínuo dos profissionais, orientado pelo projeto pedagógico do Estatuto da Criança e do Adolescente (ECA), e garantir a apuração célere e aprofundada de denúncias de abusos".

Diante dos dados apresentados podemos afirmar que o Sistema Socioeducativo situa-se em uma estreita relação com Instituições historicamente marcadas pelo conservadorismo, hierarquização e poder, cuja incorporação de estratégias de controle, através da combinação de instrumentos de repressão e consenso, legitimam um legado.

É valido destacar que o sistema de proteção integral, voltado à criança e ao adolescente é fruto de um amplo processo sócio - histórico de lutas e movimentos sociais, que foi inscrito na Constituição de 1988 e regulamentado com a promulgação do Estatuto da Criança e do Adolescente (ECA) em 1990. Com isso, institui-se um novo paradigma de proteção, sob o prisma da garantia de direitos fundamentais e sociais e do reconhecimento desse grupo populacional como sujeito de direitos.

Com o advento do ECA são instaurados procedimentos legais a serem adotados para o atendimento de adolescentes que cometem atos infracionais, como o devido processo legal, o contraditório e a responsabilização penal juvenil. Todavia, embora a legislação represente uma importante conquista social, "a implementação dos direitos da criança e do adolescente perpassa por campos de força que tencionam sempre pela recondução da intervenção sob o patamar individualizante e punitivo." (LEAL e MACEDO, 2017, p. 134).

É contraditório, ainda, analisar os dados acima descritos à luz do Sistema Nacional de Atendimento Socioeducativo (SINASE), o qual estabelece dentre todas as diretrizes pedagógicas para a execução das medidas socioeducativas: a prevalência da ação socioeducativa sobre os aspectos meramente sancionatórios, o respeito à singularidade do adolescente, presença educativa e exemplaridade como condições necessárias na ação socioeducativa; a disciplina como meio para a realização da ação socioeducativa. (Brasil, 2012)

No entanto, o desafio está em materializar as conquistas históricas obtidas no campo dos direitos, bem como a própria organização do Sistema Socioeducativo, reconhecendo que essa materialização dependerá sempre da atuação de forças na direção contra-hegemônica do capital. Portanto, Tejadas (2005) destaca que não é possível legitimar a socioeducação pela intenção,

Ela necessita de condições como: corpo profissional habilitado; políticas de educação, saúde, trabalho, profissionalização, esporte, cultura e lazer em consonância com os pressupostos do ECA; uma metodologia de trabalho que trate o adolescente com respeito e dignidade, oferecendolhe limites e responsabilidades através de um processo que possa favorecer, pela vivência, a internalização de valores e o exercício do pertencimento em estruturas dotadas de sentido. (Tejadas, 2005, p. 277)

Por essa razão, urgente e necessário se faz o debate constante em torno do Sistema Socioeducativo brasileiro, bem como o real enfrentamento e a superação dessa lógica coercitiva e punitiva tão presente nos espaços de cumprimento das medidas socioeducativas e que reforçam o caráter moralizador e de controle sobre o comportamento dos sujeitos.

Não se trata de uma tarefa fácil, principalmente diante de um tempo presente marcado pelo retrocesso dos direitos sociais e do fortalecimento dos discursos de ódio tão legitimados em nível nacional, ao passo que se alastra na mesma proporção um silêncio intencional frente ao descarado processo de violação e desproteção social das juventudes pobres. É preciso também reconhecer que adolescentes e jovens que cometem atos infracionais podem ser protagonistas de sua própria história, capazes de romper com o que está posto e estabelecido nessa sociedade capitalista contemporânea. 


\section{(Des) proteção social da adolescencia brasileira: uma face perversa da sociedade capitalista}

0 modelo de sociedade capitalista nos permite afirmar, que as últimas décadas, vêm sendo atravessadas por uma política neoliberal, desenvolvimentista, globalizada, de acúmulo de riquezas, de concentração do poder e dos meios de produção, impactando diretamente nas condições de vida, sobretudo da classe trabalhadora, que permanece distante do acesso à riqueza socialmente produzida e consequentemente vivencia a face mais perversa das desigualdades sociais.

Para Marx (2013), esse movimento antagônico revela que, para alguns acumularem demasiadas riquezas, outros acumulam pobreza. "Portanto, a acumulação de riqueza num polo é, ao mesmo tempo, a acumulação de miséria, o suplício do trabalho, a escravidão, a ignorância, a brutalização e a degradação moral no polo oposto, isto é, do lado da classe que produz seu próprio produto como capital" (p. 721).

Para Marx (2013), as consequências da acumulação, próprias do capitalismo, repercutem de forma desastrosa junto à classe trabalhadora, isso se deve ao fato de que o capital, conforme afirma Iamamoto e Carvalho (2005, p. 30) "é uma relação social de produção", assim é uma "relação burguesa de produção", e a essência de sua reprodução reside exatamente na exploração do trabalho assalariado. Para Paniago (2014, p.43)

Os trabalhadores obtêm o necessário para sua reprodução enquanto classe de trabalhadores, e os capitalistas acumulam seu capital de forma contínua e ampliada, para se manterem capitalistas, e novamente poderem comprar a força de trabalho - fonte vital da riqueza social. Portanto, a qualidade e a quantidade da partilha da riqueza a ser estabelecida tem como pressuposto o lugar que cada indivíduo ocupa na estrutura produtiva capitalista.

Mas o que está no centro dessa discussão é de que maneira isso atravessa a vida dos adolelescentes? Quais as consequências do domínio do capital sobre as relações sociais entre as classes?
Finelli (2003, p. 101), faz uma importante analise sobre o impacto dessa conjuntura:

A produção do capital subordina e assimila a si, progressivamente, todo espaço e todo o sentido da vida individual e coletiva, tornando-a funcional à produção de si como lucro ampliado. Ou seja, o capital se faz totalidade e enquanto totalidade é, ao mesmo tempo, produção de mercadorias, produção de classes, isto é, relações sociais desiguais, que terminam por se tornar opostas, e produção de formas de consciência moral, enquanto princípios de uma visão de mundo.

Isso significa dizer, conforme afirma Iamamoto (2011, p. 50), que "todo espaço ocupado pelo capital transforma-se em espaços de poder". E como espaço de poder, essa subordinação ao capital nos marcos do modo de produção capitalista sinaliza que estamos diante de uma sociedade que legitima a exploração de uma classe sobre a outra e coloca a classe trabalhadora em condição de subalternidade e luta diária pela sobrevivência, controla e reproduz a desigualdade social, naturaliza e criminaliza o processo da pobreza.

Essa face pungente do sistema capitalista recai de forma perversa junto a adolescencia sobretudo aquela que vivencia as mais perversas formas de violaçao de direitos e a essa inclui-se adolescentes que cometem atos infracionais. A pobreza, a exploração do trabalho, o desemprego, a aridez diante das precárias condições de vida denunciam uma sociedade demarcada pelas desigualdades sociais, nos moldes da expansão capitalista.

De acordo com os dados do Panorama Social da América Latina de 2017, nos anos de 2015 e 2016, os níveis de pobreza e pobreza extrema aumentaram, após mais de uma década de redução na maioria dos países. 0 número de pessoas pobres na América Latina saltou de 168 milhões no ano de 2014 para 186 milhões no ano de 2016. Já a pobreza extrema, que no ano de 2014 atingia 8,2\%, passou para 10\% em 2016. (CEPAL, 2018, p. 85)

Em relação à população infanto-juvenil, o Panorama Social destacou que a incidência da pobreza e da extrema pobreza é mais elevada entre meninos e meninas, adolescentes, jovens, mulheres e a população que mora em áreas 
rurais. Em 2016, a pobreza afetava 46,7\% das crianças e adolescentes entre 0 e 14 anos e a extrema pobreza, $17 \%$. No caso dos jovens de 15 a 29 anos esses números eram de $31,1 \%$ e 9,5\%, respectivamente.

Esse mesmo documento destaca que a desigualdade é uma característica histórica e estrutural das sociedades latino-americanas e caribenhas, que foi mantida e reproduzida mesmo em períodos de crescimento econômico. Isso parece coerente com o tipo de capitalismo periférico dependente, característico segundo Marini (2000), de uma economia exportadora e voltada ao mercado externo, que pode prescindir do consumo individual dos seus trabalhadores, tornando possível a maior exploração da forca de trabalho, ou seja, a superexploração. Para o autor, essas condições (dependência e superexploração), favorecem o aumento das desigualdades social e antagonismos, acirrando ainda mais os conflitos de classe.

Para Florestan Fernandes $(2005$, p. 323) na América Latina esse capitalismo dependente e periférico "tende a introduzir maiores desequilíbrios econômicos na base dos antagonismos de classes e controles políticos mais rígidos sobre seus efeitos". Assim, segundo o autor, nesse "capitalismo difícil", a questão social tende a se intensificar e se complexificar, colocando em risco vários segmentos da classe trabalhadora, incluindo também as juventudes.

$\mathrm{Na}$ realidade brasileira dados da UNICEF (2018), indicam que em 2015, 6,5\% da população de crianças e adolescentes, ou seja, 2.802.259 estavam fora da escola. Além disso, o estudo revela que de cada três crianças e adolescentes que não frequentam a escola, quase dois são negros. Cerca de 2.529.750 crianças brasileiras eram trabalhadores infantis. A grande maioria desses trabalhadores (83\%) está na faixa etária de 10 a 17 anos.

Esse mesmo documento aponta que 23\% da população de crianças e adolescentes no Brasil sofrem privações de seus direitos fundamentais. Além disso, 18 milhões de crianças e adolescentes no Brasil vivem em famílias com renda insuficiente, e quase seis milhões vivem em famílias cuja renda não compra uma cesta básica de alimentos. Outro dado alarmante revela o perverso recorte étnico racial que atravessa as condições de vida dessa população, as crianças e adolescentes negros têm maior probabilidade de serem pobres do que crianças e adolescentes brancos.

Segundo o estudo, foram observadas reduções importantes referentes às privações monetárias ao longo dos últimos dez anos: de $55 \%$ da população de crianças e adolescentes, em 2005, caiu para $34 \%$, em 2015. A pobreza extrema também caiu de $20 \%$ para $11 \%$. Todavia o estudo conclui que embora aparentemente o progresso tenha sido contínuo ao longo do período analisado, foi observado também que a partir de 2013 houve uma reversão da tendência, com um leve aumento entre esse ano e 2015. Para a UNICEF (2018, p.140), "certamente, tratase de um aumento leve (cerca dos dois pontos percentuais), mas é possível afirmar que a pobreza monetária deixou de baixar como ocorria e a pobreza extrema alcançou em 2015 o nível a que tinha chegado em 2011". Por fim, dentre as conclusões do estudo, destacamos:

Embora considerando as fortes limitações que enfrenta qualquer tentativa de medição como a que foi realizada nesta pesquisa, é possível determinar que aproximadamente $50 \%$ da população de crianças e adolescentes do país têm seus direitos violados de uma maneira ou outra; e que $19 \%$ registram ao menos uma violação definida aqui como extrema. Um dos aspectos mais destacados do estudo é a desigualdade por cor: crianças e adolescentes negros registram uma taxa de pobreza ou violação de direitos de $58 \%$, em comparação com $38 \%$ dos brancos; e uma taxa de pobreza extrema de $24 \%$, em comparação com 13\% dos brancos. (UNICEF, 2018, p. 151)

Os dados descritos situam a adolescencia brasileira nas fronteiras da subalternidade, e muito precocemente essas experimentam os mais perversos impactos da violação de direitos e da (des) proteção social.

A resposta do Estado a essa complexa situação mostra-se frágil à medida que se consolida a partir de políticas compensatórias, seletivas e fragmentadas, as quais, alicerçadas nas bases do discurso conservador que se alastra no tempo presente, permitem ainda que o compromisso com os ideais neoliberais seja fortalecido e propagado. 
É preciso compreender que as desigualdades sociais, consolidadas no modelo vigente de sociedade, são resultado da riqueza socialmente produzida e acessada por poucos, bem como do processo de concentração do poder. A pobreza se alastra ao passo que aumenta a distância entre ricos e pobres, o que não se trata de uma mera coincidência. Para Netto (2007, p. 142) esse movimento do "desenvolvimento capitalista, é necessário e irredutivelmente, produção exponenciada de riqueza e produção reiterada da pobreza".

Por essa razão, mais do que nunca, os adolescentes, em especial aqueles que se encontram em situação de risco e vulnerabilidade, necessitam, segundo Scherer (2013: p. 33), "de reconhecimento, sendo que este vêm ao encontro da valorização das potencialidades e resistências que o segmento carrega consigo." Portanto se faz necessário observar as necessidades desse segmento social, por vezes invisibilizado na sociedade, a fim de produzir política públicas não só de caráter coercitivo, mas que dêem conta das complexas questões que envolvem esses sujeitos.

\section{Considerações finais}

Para mim, é impossível existir sem sonho. A vida na sua totalidade me ensinou como grande lição que é impossível assumi-la sem risco. (Paulo Freire)
Diante do contexto apresentado, é preciso considerar que o tempo presente nos coloca em estado de alerta, uma vez que a violação de direitos destes sujeitos representa um retrocesso das conquistas dos movimentos sociais e demais militantes, referente ao paradigma de proteção integral e da ampliação dos preceitos estabelecidos no ECA e no SINASE, o que traz à tona a necessidade de luta em defesa da garantia desses direitos, bem como a resistência frente às medidas de cunho repressivo/coercitivo, que mascaram a necessidade de manutenção da ordem socialmente estabelecida pelo capital em detrimento da ampliação de políticas públicas realmente capazes de sustentar um modelo de proteção social integral.

Podemos afirmar, com base na realidade brasileira que a fragilidade do Estado no enfrentamento da intensificação das expressões da questão social resulta em políticas compensatórias, seletivas e fragmentadas, as quais permitem que o compromisso com os ideais neoliberais seja fortalecido.

Por essa razão, mais do que nunca, se faz necessário analisar e apreender as necessidades desse segmento social, por vezes invisibilizado na sociedade, a fim de produzir políticas públicas não de caráter coercitivo, mas que deem conta das complexas questões que envolvem esses sujeitos. 
Capitalismo, questão social e (des) proteção social de adolescentes autores de ato infracional...

\section{Referências}

Baumam, Z. (2001). A sociedade individualizada: vidas contadas e histórias vividas. Rio de Janeiro: Zahar.

Brasil, Ministério dos Direitos Humanos (MDH). (2018). Levantamento Anual Sinase 2015. Brasília: Ministério dos Direitos Humanos.

BrasiL, Lei no 8.069 de 13 de julho de 1990. Dispõe sobre o Estatuto da Criança e do Adolescente. 1990. Diario Oficial da União, Poder Legislativo, Brasília, DF, 13 jul. 1990. Disponivel em: http://www.planalto.gov.br/ccivil_03/leis/18069.htm>. Acesso em: 14 de julho de 2019.

Brasil, Lei no 12.594 de 18 de janeiro de 2012. Dispõe sobre o Sistema Nacional de Atendimento Socioeducativo (SINASE). 2012. Diario Oficial da União, Poder Legislativo, Brasília, DF, 12 jan. 2012. Disponivel em: http://www.planalto.gov.br/ccivil_03/_Ato20112014/2012/Lei/L12594.htm. >. Acesso em: 14 de julho de 2019.

Comisión Económica para América Latina y el Caribe (CEPAL). (2018). Panorama Social de América Latina, 2017 (LC/PUB.2018/1-P), Santiago.

Fernandes, F. (2005). A revolução burguesa no Brasil: ensaio de interpretação sociológica. São Paulo: Globo.

Fundo das Nações Unidas. (2018). Bem estar e privações múltiplas na infância e adolescência no Brasil. Brasil: UNIFEC.

Imamoto, M. V. (2001). O serviço social na contemporaneidade: trabalho e formação profissional. São Paulo: Cortez.

- (2011). Serviço social em tempo de capital fetiche: capital financeiro, trabalho e questão social. São Paulo: Cortez.

Iamamoto, M. V.; Carvalho, R. de. (2005). Relações sociais e serviço social no Brasil: esboço de uma interpretação histórico-metodológica. São Paulo: Cortez.

Instituto Sou da Paz (2018). Aí eu voltei para o corre: Estudo da reincidência infracional do adolescente no Estado de São Paulo. São Paulo: Instituto Sou da Paz.

Leal, D. M.; Macedo, J. P. (2017). A penalização da miséria no Brasil: os adolescentes "em conflito com a lei". Textos \& Contextos, 16(1), pp. 128-141, jan./jul. <https://doi.org/10.15448/16779509.2017.1.24550>.

Marini, R. M. (2000). Dialética da dependência. São Paulo: Editora Vozes.

Marx, K. (2010). Glosas críticas marginais ao artigo "O rei da Prússia e a reforma social". Por um prussiano. São Paulo: Expressão Popular.

- (2013).O capital. Livro 1. Critica a economia política. São Paulo: Boitempo.

Paniago, M. C. S. (2014). Crise estrutural e a centralidade das classes sociais. R. Katál., 17(1), p. 41-49, jan./jun.

Paulo Netto, J. (2007). Desigualdade, pobreza e Serviço Social. Em Pauta, 19, pp. 134-170.

Scherer, G. (2013). Serviço social e arte: juventudes e direitos humanos em cena. São Paulo: Cortez.

Scisleski, A. C. C. et al. (2015). Medida socioeducativa de internação: estratégia punitiva ou protetiva? Psicologia e Sociedade, pp. 505-515.

Tejadas, S. S. (2005). Juventude e ato infracional: as múltiplas determinações da reincidência. 2005. Dissertação (Mestrado em Serviço Social) - Pontifícia Universidade Católica do Rio Grande do Sul, Porto Alegre.

Zaffaroni, E. R. (2012). A palavra dos mortos: conferências de criminologia cautelar. São Paulo: Saraiva. Wacquant, L. (2001). As prisões da miséria (trad. André Telles). Rio de Janeiro: Jorge Zahar. 